\title{
Development of analytical methods for polycyclic aromatic hydrocarbons (PAHs) in airborne particulates: A review
}

\author{
LIU Li-bin ${ }^{1}$, LIU Yan ${ }^{1}$, LIN Jin-ming ${ }^{1, *}$, TANG Ning ${ }^{2}$, HAYAKAWA Kazuichi ${ }^{2}$, MAEDA Tsuneaki $^{3}$ \\ 1. State Key Laboratory of Environmental Chemistry and Ecotoxicology, Research Center for Eco-Environmental Sciences, \\ Chinese Academy of Sciences, Beijing 100085, China. E-mail: lbliu@mails.gucas.ac.cn \\ 2. Graduate School of Natural Science and Technology, Faculty of Pharmaceutical Sciences, Kanazawa University, \\ Kakuma-machi, Kanazawa 920-1192, Japan \\ 3. Innovation Center for Start-ups (INCS), National Institute of Advanced Industrial Science and Technology, \\ 2-2-2 Marunouchi, Chiyodaku, Tokyo 100-0005, Japan
}

Received 26 April 2006; revised 28 June 2006; accepted 10 July 2006

\begin{abstract}
In the present work, the different sample collection, pretreatment and analytical methods for polycyclic aromatic hydrocarbons (PAHs) in airborne particulates is systematacially reviewed, and the applications of these pretreatment and analytical methods for PAHs are compared in detail. Some comments on the future expectation are also presented.
\end{abstract}

Key words: polycyclic aromatic hydrocarbons (PAHs); airborne particulates; analytical methods; review

\section{Introduction}

Polycyclic aromatic hydrocarbons (PAHs) are a class of several hundred individual compounds defined to be composed of two or more fused aromatic rings. PAHs are of concern because certain of them are classified as probable human carcinogens (IARC, 1983; IPCS, 1998; UNECE, 1998; Vestreng and Klein, 2002) and show tumorigenic activity and endocrine disrupting activity in mammals (Cavalieri and Rogan, 1998). Recently the regulations of PAHs have been enacted or proposed in Europe and by the WHO (Bostrofm et al., 2002; WHO, 2000; WHO/IPCS, 1998).

Unsubstituted PAHs are formed mainly by the incomplete combustion of organic materials (Baek et al., 1991; Mastral et al., 2000a). And the atmospheric photochemical PAH reactions cause to form many kinds of substituted PAHs, such as nitrated PAHs (NPAHs), hydroxylated PAHs (OH-PAHs), amino-PAHs (APAHs) and so on. For example, NPAHs are formed easily by the reaction of PAH with reactive species found in ambient air, such as dinitrogen pentoxide $\left(\mathrm{N}_{2} \mathrm{O}_{5}\right)$ and oxygen radicals in the presence of nitrogen oxides and hydroxylated radicals. During the last three decades, a great deal of health research interest focused on the mutagenicity and carcinogenicity of PAHs and their oxidation products (Ames et al., 1975; FinlaysonPitts and Pitts, 1999; Mersch-Sudermann et al., 1993). And

Project supported by the National Natural Science Foundation of China (No. 20437020; 20575073), NSFC-JSPS Joint Research Project (No. 20511140134) and the Major Research Program of Chinese Academy of Sciences (KZCX3-SW-432); *Corresponding author.

E-mail: jmlin@rcees.ac.cn. the results showed some of substituted PAHs may be more toxic than the parent PAHs. PAHs and their derivatives are directly emitted by diesel and petrol engines, industrial processes, coal combustion, cigarette smoke, and have also been found in carbon black and photocopier toners, fly ash, exhaust emission from waste incineration plants (Barzegar and Dasgupta, 1996; Cvacka et al., 1998; Jacob et al., 1991; Kirton and Crisp, 1990; Lee et al., 1998; Marr et al., 1999; Mastral et al., 1999; Moreira et al., 1996; Oamh et al., 1999; Wilhelm et al., 2000; Xu et al., 2006; Zimmermann et al., 1999). Hayakawa et al. (1995a, $1995 \mathrm{~b})$ reported that automobiles are a main source of atmospheric PAHs and NPAHs. PAHs and their derivatives need to be monitored in time, which is benefit to value the quality of air and infer the source of pollutants.

Due to the PAHs high volatility, PAHs from energy generation can be released both supported onto the particulate matter (PM) and/or in the gas phase (Mastral et al., 2000b, 2001). The most volatile compounds with two or three aromatic rings, are mainly released in the gas phase, while compounds containing more than three aromatic rings, are generally associated with the PM emission. The PAHs gas/solid partitioning is related to many different variables like the liquid vapor pressure, the ambient temperature and the size, chemical composition and surface area of the PM. These characteristics, together with the PAHs volatile character, will determine the way in which they are emitted to the atmosphere. The U.S. Environmental Protection Agency (EPA) promulgated a new size-specific air quality standard for environmental particulate matter in 1987 (EPA, 1987). This new standard 
applies only to particulate with diameters smaller than or equal to $10 \mu \mathrm{m}\left(\mathrm{PM}_{10}\right)$ and replaces the original standard for total suspended particulate matter (TSP). Nowadays, $\mathrm{PM}_{2.5}$ and aerosols with $1.0 \mu \mathrm{m}$ or less in diameter are being taken into account because they represent the particle fraction inhaled into the deeper respiratory tract regions. In addition, PAHs are concentrated in the submicro-PM due to gaseous PAHs condensation into the smallest particles.

Sensitive, rapid, simple and accurate methods have been developed to determine PAHs and their derivatives in the atmospheric particles. As high efficient separation tools, GC and HPLC have been used for determining all kinds of samples containing complex components. GC-FID, GCMS, HPLC-FL (Silvestre et al., 1986; Wilhelm et al., 2000) are the conventional analytical methods to determine the unsubstituted PAHs. And the substituted PAHs, such as NPAHs, most of these compounds are low volatile and instable, are mainly determined by HPLC. And the continuing use of LC methods for the determination of NPAHs is documented by the increase in the number of published paper (Cvacka et al., 1998). Method of the combination of HPLC with fluorescence (Tejada et al., 1986), chemiluminescence (Hayakawa et al., 1995a) and electrochemical detection (Jin and Rappaport, 1983; Kuo et al., 2003) have been developed. GC-NPD and GCNICIMS (David et al., 1982) are also used for determining the 2- or 3-rings NPAHs and have good selectivity and sensitivity.

The direct determination of extremely trace PAHs and their derivatives by modern high efficient chromatographic techniques is still very difficult. The limitations are associated not only with the insufficient sensitivity of these techniques but with matrix interference. For this reason, the separation and preconcentration techniques are often required. For the atmospheric particulates sample, extraction methods of PAHs and their derivatives include traditional Soxhlet extraction, ultrasonic extraction, supercritical fluid extraction, microwave-assisted extraction and accelerated solvent extraction. Solid phase extraction is often followed for clean-up the interference of the extraction liquid.

But the analysis of atmospheric PAHs faces many problems: the airborne particulate samples are extremely complex, and often contain many different classes of compounds in varying amounts; many studies are incompatible due to differences in results caused by differences in analysis techniques: very low concentration required more sensitive analytical methods which are not suitable for larger quantities; the most common atmospheric PAHs sampling uses filters or adsorbents, which are not proper for the most volatile species and can be lost before detection and/or other species cannot be totally extracted once adsorbed; PAHs deposition with the PM greater than $3-$ $5 \mu \mathrm{m}$ and/or gas PAHs re-volatilisation once deposited; strong influence of the meteorological conditions; strong influence of the ambient contaminants, and so on.

Researchers in many countries have made much effort to the analysis of PAHs in airborne particulates. This paper summarizes the PAHs data in airborne particulates to help understand the sample collection, pretreatment and analytical methods of PAHs.

\section{Analytical methods for PAHs in airborne particulates}

\subsection{EPA standard analytical method for atmospheric PAHs}

Under the sponsorship of EPA, Method TO-13 was originally published in March of 1989 as one of a series of peer-reviewed methods in the second supplement to "compendium of methods for the determination of toxic organic compounds in ambient air", EPA 600/4-89-018. In an effort to keep these methods consistent with current technology, Method TO-13 has been revised and updated as Method TO-13A "determination of polycyclic aromatic hydrocarbons (PAHs) in ambient air using gas chromatography/mass spectrometry (GC/MS)". This compendium incorporates new or improved sampling and analytical technologies. The summary of Method TO-13A is as following (EPA, 1999):

(1) Filters and sorbent cartridges (containing PUF or $X A D-2)$ are cleaned in solvents and vacuum dried. The filters and sorbent cartridges are stored in screw-capped jars wrapped in aluminum foil (or otherwise protected from light) before careful installation on the sampler.

(2) Approximately $300 \mathrm{~m}^{3}$ of air is drawn through the filter and sorbent cartridge using a high-volume flow rate air sampler or equivalent.

(3) The amount of air sampled through the filter and sorbent cartridge is recorded, and the filter and cartridge are placed in an appropriately labeled container and shipped along with blank filter and sorbent cartridges to the analytical laboratory for analysis.

(4) The filters and sorbent cartridge are extracted by Soxhlet extraction with appropriate solvent. The extract is concentrated by Kuderna-Danish (K-D) evaporator, followed by silica gel cleanup using column chromatography to remove potential interferences prior to analysis by GC/MS.

(5) The eluent is further concentrated by K-D evaporation, then analyzed by GC/MS. The analytical system is verified to be operating properly and calibrated with five concentration calibration solutions.

(6) A preliminary analysis of the sample extract is performed to check the system performance and to ensure that the samples are within the calibration range of the instrument. If the preliminary analysis indicates nonperformance, then recalibrate the instrument, adjust the amount of the sample injected, adjust the calibration solution concentration, and adjust the data processing system to reflect observed retention times, and so on.

(7) The samples and the blanks are analyzed and used (along with the amount of air sampled) to calculate the concentration of PAHs in the air sample.

\subsection{Some analytical methods for atmospheric PAHs}

With the development of technology, the analytical methods for PAHs are growing. It is probably true to 
say that advances in environmental analyses have more or less occurred concomitantly with those in the analytical methods. A cursory examination of accepted and certified methods of analysis of many environmental pollutants indicates that chromatographic techniques play a significant role, and may well be the most widely used procedures in this area of application. More specifically, chromatography is a principal technique in the analysis of air pollutants; the continued advent of new or improved instrumentation and novel column technologies have meant that chromatography has remained at the forefront in this area of research, and its preeminent position appears unchallenged in the foreseeable future. A wide number of techniques have been developed for the determination of PAHs in the airborne particulate matter, such as thin-layer chromatography (TLC), gelpermeation chromatography (GPC), gas chromatography (GC), gas chromatography-mass spectrometry (GC/MS) and high-performance liquid chromatography (HPLC), etc. Chromatographic techniques such as GC or HPLC coupled with fluorescence, UV, FID and MS detectors are the most frequently used now. As reported, HPLC has been successfully used to analyze PAHs for more than twenty years. It has become one of the most effective methods for monitoring PAHs. Compared with GC method, HPLC, especially reverse phase HPLC (RP-HPLC), can analyze the compounds without the considering of volatility and molecular weight, moreover, it shows good selectivity and high sensitivity. HPLC with ultraviolet absorption detector or fluorescence detector was used to determine atmospheric PAHs by many groups (Lee and Lee, 2004; Li and Ro, 2000; Venkataraman et al., 1999; Yutaka et al., 2005; Zhu and Wang, 2003). GPC was found to be good for PAHs isomers and derivations (Fernandez and Baynoa, 1992; Lohmann et al., 2001). GC/MS was also widely used in the determination of PAHs according to its superiority in qualitative and quantitative analysis (Allen et al., 1996; Chen et al., 2005; Gigliotti et al., 2005; Lee et al., 1995, 2001; Ochsenkuhn-Petropoulou et al., 2003; Possanzini et al., 2004).

In addition, some biologic methods also have been applied in the determination of PAHs. Li et al. (1999) developed sensitive enzyme-linked immunosorbent assays (ELISAs) for multianalyte detection of PAHs. The haptens with different lengths of carboxylic acid spacers at various positions were derived from PAHs. And these haptens were coupled with bovine serum albumin to form competitor conjugates. All of the haptens were recognized to different extents by monoclonal antibodies 4D5 and 10C10. Cigamek et al. (2004) realized a combined chemical and bioassay analysis of traffic-emitted PAHs. And Angerer et al. (1997) reviewed biological monitoring and biochemical effect monitoring of exposure to PAHs.

\subsection{Analytical methods for nitro-PAHs and other PAHs derivatives}

Oxygenated and nitro-substituted polycyclic aromatic hydrocarbons (oxy- and nitro-PAHs, respectively) are formed in the combustion of fuel, natural gas, wood, coke and in residue incineration. They are present in tobacco smoke and also in the ambient air due to chemical reactions of PAHs with different atmospheric pollutants, such as $\mathrm{NO}_{x}$ or $\mathrm{O}_{x}$ (Alebic-Juretic et al., 1990; Fan et al., 1995; Pitts et al., 1978; Xu and Burlingame, 1988). The direct mutagenic activity of tobacco smoke or atmospheric extracts has been mainly correlated with the presence of oxy- and nitro-PAHs (Bayona et al., 1994; Casellas et al., 1995; Yu et al., 2002). While PAHs have proved to be indirect mutagens, nitro-PAHs are direct-acting mutagens.

Analytical techniques which have high resolution and specificity are required for the determination of a large number of NPAHs and related compounds in environmental samples. GC is used for determining nitro compounds because of its high resolution, sensitive and selective detection. Many types of detectors have been developed for nitro compounds. These include electron capture detector (ECD), nitrogen and phosphorus selective detector (NPD), thermionic ionization detector (TID) operated in a nitrogen atmosphere, chemiluminescence detector (CLD) and mass spectrometry (MS) (Marino et al., 2000; Schnelle-Kreis et al., 2001). The most selective and sensitive techniques for the detection of oxy- and nitro-PAHs are based on electron capture processes occurring in the gas phase, due to the electronegative character of the nitro and oxy groups conjugated with the aromatic rings. This allows the detection of low concentrations and a higher degree of selectivity than in other types of common detectors. Thus, negative ion chemical ionization mass spectrometry (NCIMS) (Bezabeh et al., 2003; Dusek et al., 2002; Ramdahl and Urdal, 1982; Siegmund et al., 2003) and ECD (Xu and Lee, 2001) are the most widely used techniques for the analysis of oxy- and nitro-PAHs, showing the lowest limits of detection. Xu and Lee (2000) also developed a derivatization-GC/ECD analytical method to identify and quantify NPAHs in atmospheric particulate matter.

The nitro-group of NPAHs is electrochemically, chemically or metal-catalytically reduced to a nitroso group, a hydroxyamino group and then an amino group (Hayakawa, 2000). The resulting amino-PAHs (APAHs) are fluorescent and this reaction pathway is very useful for the sensitive and selective detection of NPAHs. HPLC with different kinds of detection techniques for NPAHs has been reviewed (Cvacka et al., 1998). NPAHs can be separately determined by HPLC with electrochemical detection (HPLC/ECD) (Galceran and Moyano, 1993). Other papers concerning HPLC with chemiluminescence and fluorescence detections (CLD and FLD) for NPAHs have also been reported or reviewed (Hayakawa et al., 1992, 1999a, b; Taga et al., 2005; Tang et al., 2004). The schematic diagram of typical HPLC/CLD analytical system is shown in Fig. 1 (Tang et al., 2003). The HPLC system in Fig. 1 was operated as follows. After the sample was introduced into the system, the NPAHs were separated from interfering substances on the clean-up column. Then by changing the position of the switching valve, the APAHs which were produced by passing the NPAHs through the reducer column, were concentrated on the concentrator column by adding the ascorbic acid solution from pump 2 to the 


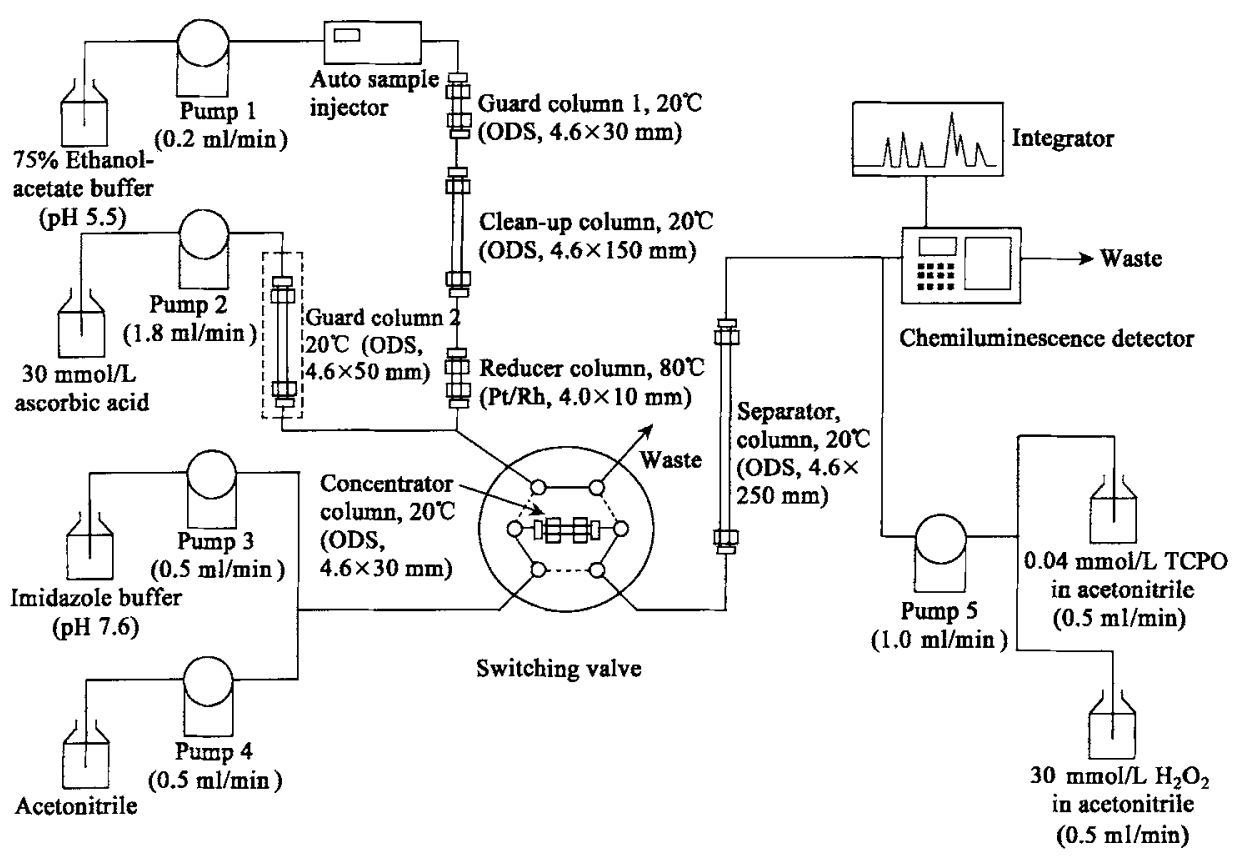

Fig. 1 Schematic diagram of typical HPLC/CLD analytical system (Tang et al., 2003).

effluent from the reducer column to increase the water concentration. After all APAHs were eluted from the clean-up column and concentrated on the concentrator column completely, the APAHs were eluted into the separator column with a mixture of buffer (from pump 3) and acetonitrile (from pump 4) by changing the position of the switching value. Then the APAHs are separated on the separator column and detected by chemiluminescence. And as mentioned above, NPAHs are not fluorescent but most APAHs are strongly fluorescent. So in order to apply HPLC/FLD to NPAHs, NPAHs must be reduced. Both offline and on-line reduction methods have been reported (Hayakawa et al., 1993, 2002; Murayama and Dasgupta, 1996). In addition, only a few studies have been reported concerning LC-MS of NPAHs (Bonfanti et al., 1996). But the sensitivity of LC-MS is not enough for NPAHs at trace levels in environmental samples. A few studies concerned the analysis of PAHs and NPAHs by low-temperature Shpol'skii fluorescence/luminescence spectroscopy (Kozin et al., 1996; Matsuzawa et al., 1995).

\section{Sampling and pretreatment methods for PAHs in airborne particulates}

\subsection{Sampling methods for PAHs}

The sampling techniques for PAHs have been improved in last two decades. A number of researches showed that the main sampling modes for atmospheric PAHs are active sampling and passive sampling. The samplers used mainly are high-volume sampler and impingement cascade sampler. Sorbent, filter, impingement collector, etc. are usually used to collect target compounds in active sampling. And passive sampling is due to the migration of target compounds through concentration gradient. Passive sampling has been successfully applied to environmental monitoring, particularly in the analysis of gaseous PAHs and other little organic compounds in the air. It is a popular sampling technique because it is portable, noiseless and lower cost. Semipermeable membrane devices (SPMDs) used as passive samplers have been reported (Soderstrom and Bergqvist, 2004; Soderstrom et al., 2005). A standard semi-volatile sampling train with a filter was also used to collect PAHs (Sheu et al., 1997).

In many applications, filters were used to collect the particle-bound PAHs while solid sorbent was used to collect gaseous volatile PAHs. As reported, glass fiber filter (Bi et al., 2003; Lin et al., 2002; Simcik et al., 1999; Tsai et al., 2002), quartz fiber filter (Gigliotti et al., 2005; Okuda et al., 2002), cellulose filter (OchsenkuhnPetropoulou et $a l ., 2003$ ) were the filters mostly used to collect particle-bound PAHs. And the choice of sorbent is very important in the collection of gaseous volatile PAHs. The sorbent should has high collection efficiency, large adsorb capacity and chemical stability. Most sorbent used to collect gaseous PAHs were Tenax, XAD-2, polyurethane form (PUF), Florisil, Seppark- $\mathrm{C}_{18}$ and so on. Thereinto PUF and XAD-2 are mostly used due to their advantages of low-cost and tractable.

For different size particles, there are some different methods to collect them. $\mathrm{PM}_{10}$ and $\mathrm{PM}_{2.5}$ samples can both be collected by high-volume samplers. But for data comparison, low-volume sampler with 10 or $2.5 \mu \mathrm{m}$ inlet was used to collect $\mathrm{PM}_{10}$ and $\mathrm{PM}_{2.5}$ samples, respectively (Guo et al., 2003). In addition, airborne particles were collected and size-fractionated using a sampler that combined a minipump with a three-stage cascade impactor. Different kinds of filters were used to collect different size particles (Ohura et al., 2004).

It should be noted that it is better to reduce the sampling time especially in the collection of gaseous PAHs. Until now, both high-volume and low-volume samplers 
can collect the particle-bound PAHs, but they have still needed some improvements to monitor the gaseous PAHs exactly. How to avoid the volatilization and loss of PAHs in the sampling, the reaction between PAHs and other compounds and the redistribution among different size particles still need more effort. A modified high-volume sampling-with an oxidant denuder system added, in order to minimize the PAH degradation during air sampling, was reported recently (Tsapakis and Stephanou, 2005a, b).

\subsection{Preservation and pretreatment of air samples}

\subsubsection{Preservation of samples}

Volatilization and loss of PAHs may occur on the filter and sorbent. So the preservation of samples should be very careful. Usually, each filter should be folded with the adsorbed particulate matter on the inner side, wrapped in an aluminum foil to protect them from light and kept under refrigeration at low temperature (about $-18^{\circ} \mathrm{C}$ ) until extraction and analysis (Dallarosa et al., 2005a; Sanderson and Farant, 2005; Wu et al., 2006).

\subsubsection{Pretreatment of samples}

The air matrix is complicated and the concentration of PAHs in the air is very low, so the pretreatment of samples is a very important step for the determination of PAHs. Song and Lin (2005) reviewed sample pretreatment techniques for PAHs in environmental matrix. Dichloromethane, acetonitrile, benzene, toluene, cyclohexane and their mixture are usually used as extraction solvent. Solvent extraction (such as Soxhlet extraction, ultrasonic extraction, supercritical fluid extraction (SFE), microwave-assisted extraction (Lee et al., 2001), accelerated/pressurized solvent extraction), concentration (such as K-D evaporator (Bae et al., 2002; Cecinato et al., 1999; Zhang et al., 2005) and rotary evaporator concentration (Chetwittayachan et al., 2002)) and clean-up with columns (Hafner and Hites, 2005) are three mostly applied pretreatment methods for PAHs samples. And subcritical water extraction has also been applied as pretreatment of air samples (Romero et al., 2002).

Soxhlet extraction is a classical method due to its high extraction efficiency. Yang et al. (1999) determined polycyclic aromatic hydrocarbon concentrations in extract solvent of airborne particulate in different steps of Soxhlet extraction, and drawn out the Soxhlet extraction curves, then found the extract efficient mainly depended on extract cycle numbers, did not depend on extract soak time. By comparing Soxhlet extract efficient of eleven kinds of extract solvents to adding standard reference matter and research reference matter, they found cyclohexane and benzene as extract solvents most in use were not so well efficient extract solvents. The order of extract efficient of the extract solvents is as follow: quinoline-ethanol, pyridineethanol, acetone, ethanol, dichloromethane, benzene, cyclohexane, petroleum ether, acetone-ethanol-cyclohexane, trichloromethane, and tetrahydrofuran. Dallarosa et al. (2005b) used Soxhlet extraction technique to identify and quantify the main sources of PAHs associated with aerosols $\left(\mathrm{PM}_{10}\right)$ collected at three different sampling sta- tions. Fang et al. (2004) used dichloromethane/hexane as solvent to Soxhlet extract PAHs and simultaneously measured PAHs from 2002-2003. But it is time-consuming (about several hours) for the extraction of PAHs and further concentration need to do because of the large amount of solvent.

Ultrasonic extraction is a popular method for PAHs because it is time-saved, solvent-saved and high efficiency. Park et al. (2002) applied ultrasonic extraction for PAHs and followed by GC/MS determination. They analyzed the concentrations of PAHs in different sites in Korea. Some authors such as Hayakawa et al. (2002), Tang et al. (2005), Bi et al. (2005), Duan et al. (2005) all applied ultrasonic extraction technique.

Supercritical fluid extraction (SFE) also has been applied in the analysis of atmospheric PAHs. It has high extraction efficiency, good selectivity. It is time-saved and can not induce secondary pollution. What's more, it can be easily coupled with GC, GC-MS, HPLC, etc. Shimmo et al. (2004) analyzed the PAHs by on-line SFE-LC-GCMS. The operation was simple and largely reduced the loss of targets. The solvent used in SFE usually are $\mathrm{CO}_{2}$, $\mathrm{NH}_{3}$, ethylene, ethane, $\mathrm{N}_{2} \mathrm{O}$, propane, propylene and $\mathrm{H}_{2} \mathrm{O}$. Castells et al. (2003) reported on the applicability of SFE for the analysis of oxy-and nitro-PAHs in particulate matter using a simultaneous extraction and clean up procedure. The developed SFE method was applied to the analysis of PAH derivatives using GC-ECD and GC-MS. It need not to purify compared with other methods. Yang et al. (1995) studied the effect of temperature and modifier on the supercritical $\mathrm{CO}_{2}$ extraction. They found that properly increasing the temperature and the addition of modifier can increase the recovery of PAHs. The most additive used is methanol. Peltonen and Kuljukka (1995) compared some different pretreatment methods for PAHs and found that SFE has much higher extraction efficiency than Soxhlet extraction.

Wu et al. (2006) applied accelerated solvent extraction and analyzed particle size distributions of PAHs in Tianjin, China. Perraudin et al. (2005) analyzed particle-bound PAHs using pressurized fluid extraction followed by GCMS recently. Zhou et al. (2005b) also developed a micro pressurized liquid extraction device for the determination of PAHs on PM $_{10}$ samples.

In addition, Koziel et al. (2001) improved a needle trap device and commercial poly (dimethylsiloxane) (PDMS) $7-\mu \mathrm{m}$ film thickness solid-phase microextraction (SPME) fibers for the sampling and analysis of air samples. The air volumes ranged from 0.1 to $50 \mathrm{ml}$ and the sampling times varied from $10 \mathrm{~s}$ to $16 \mathrm{~min}$. Results suggested the method should be a simple, fast, reusable and cost-effective screening tool. Kolar et al. (2004) also used SPME for atmospheric PAHs and estimated distribution coefficients between air and PDMS coated fiber. But until now, SPME has not been popularly used for the PAHs in the air.

The applications of pretreatment and analytical methods for PAHs in airborne particulates since 2000 are summarized and compared in Table 1 . It can be concluded from the table that GC-MS and HPLC are the analytical 
Table 1 Applications of pretreatment and analytical methods for PAHs in airborne particulates since 2000

\begin{tabular}{|c|c|c|c|}
\hline Analyte & Pretreatment method & Analytical method & Reference \\
\hline 13 PAHs & $\begin{array}{l}\text { Soxhlet extraction (dichloromethane/acetone }=5: 1 \text { ), column chromatography on } \\
\mathrm{Al}_{2} \mathrm{O}_{3} \text {, elute with dichloromethane }\end{array}$ & GC-MS & Cecinato et al, 2000 \\
\hline 5 PAHs & $\begin{array}{l}\text { Soxhlet extraction (dichloromethane/acetone }=3: 1 \text { ), column chromatography on } \\
\mathrm{Al}_{2} \mathrm{O}_{3} \text {, elute with dichloromethane }\end{array}$ & GC-MS & Cecinato et al., 2003 \\
\hline 14 EPA-PAHs & $\begin{array}{l}\text { Dialysis in cyclopentane/dichloromethane for } 48 \mathrm{~h} \text {, rotary evaporation, GPC and } \\
\text { silica gel column clean-up }\end{array}$ & GC-MS & $\begin{array}{l}\text { Soderstrom and } \\
\text { Bergqvist, } 2004\end{array}$ \\
\hline 15 EPA-PAHs & $\begin{array}{l}\text { Dialysis in cyclopentane/dichloromethane for } 48 \mathrm{~h} \text {, rotary evaporation, } \\
\text { GPC and silica gel column clean-up }\end{array}$ & GC-MS & Soderstrom et al., 2005 \\
\hline 22 PAHs & Soxhlet extraction by dichloromethane for $8 \mathrm{~h}$, evaporate concentration & $\begin{array}{l}\text { HPLC-UVD } \\
\text { HPLC-FLD }\end{array}$ & Kameda et al., 2005 \\
\hline 15 PAHs & $\begin{array}{l}\text { Dialysis in hexane for } 48 \mathrm{~h} \text {, silica gel/alumina column clean-up, elute with } \\
\text { dichloromethane/hexane, GPC clean-up }\end{array}$ & GC-MS & Lohmann et al., 2001 \\
\hline 21 PAHs & $\begin{array}{l}\text { Soxhlet extraction ( } n \text {-hexane/dichloromethane, } v: v=1 ; 1 \text { ) for } 24 \mathrm{~h} \text {, concentration, } \\
\text { clean-up, reconcentration }\end{array}$ & GC-MS & Tsai et al, 2002 \\
\hline 12 PAHs & Ultrasonic extraction with dichloromethane/acetonitrile, evaporate concentration & HPLC-FLD & Zhu and Wang, 2003 \\
\hline I5 PAHs & Ultrasonic extraction with dichloromethane/hexane, rotary evaporation & RP-HPLC-FLD & $\mathrm{Li}$ and Ro, 2000 \\
\hline 7 PAHs & Ultrasonic extraction with dichloromethane, column chromatography & $\begin{array}{l}\text { GC-MS } \\
\text { HPLC-FLD }\end{array}$ & $\begin{array}{l}\text { Schnelle-Kreis et al., } \\
2001\end{array}$ \\
\hline 16 EPA-PAHs & $\begin{array}{l}\text { Ultrasonic extraction } 3 \text { times with dichloromethane, rotary evaporation, } \\
\text { silica-alumina column clean-up, elute with dichloromethane/hexane }\end{array}$ & GC-MS & Guo et al., 2003 \\
\hline 18 PAHs & Ultrasonic extraction with dichloromethane, centrifugation, evaporation under $\mathrm{N}_{2}$ & HPLC-FLD & Ohura et al., 2004 \\
\hline 51 PAHs & $\begin{array}{l}\text { Soxhlet extraction with acetone for } 20 \mathrm{~h} \text {, rotary evaporation, silica gel column } \\
\text { clean-up, elute with } n \text {-hexane/methylene chloride }\end{array}$ & GC-MS & Okuda et al., 2002 \\
\hline 2I PAHs & $\begin{array}{l}\text { Soxhlet extraction with dichloromethane } / n \text {-hexane for } 24 \mathrm{~h} \text {, concentration, } \\
\text { clean-up, reconcentration }\end{array}$ & GC-MS & Lin et al., 2002 \\
\hline 24 PAHs & $\begin{array}{l}\text { Soxhlet extraction with } n \text {-hexane for } 24 \mathrm{~h} \text {, rotary evaporation, silica gel column } \\
\text { clean-up, elute with } n \text {-hexane/toluene }\end{array}$ & GC-MS & $\begin{array}{l}\text { Tsapakis and Stephanou, } \\
2005 \mathrm{a}\end{array}$ \\
\hline 16 EPA-PAHs & No pretreatment method & Pyrolysis/GC-MS & $\begin{array}{l}\text { Ochsenkuhn-Petropoulou } \\
\text { et al., } 2003\end{array}$ \\
\hline 16 EPA-PAHs & Ultrasonic extraction 3 times with dichloromethane & GC-MS & Bi et al., 2005 \\
\hline 14 PAHs & $\begin{array}{l}\text { Soxhlet extraction with dichloromethane/petroleum ether for } 24 \mathrm{~h} \text {, } \\
\text { rotary evaporation, alumina silica column clean-up, elute with dichloromethane }\end{array}$ & GC-MS & Vardar et al., 2004 \\
\hline 21 PAHs & Soxhlet extraction with dichloromethane/methanol $(9 / 1), K-D$ concentration & GC-MS & Possanzini et al., 2004 \\
\hline 12 PAHs & Soxhlet extraction with methylene chioride for $20 \mathrm{~h}$, fractionation & GC-MS & Vasconcellos et al., 2003 \\
\hline 18 PAHs & Microwave-assisted extraction with dichloromethane, rotary evaporation & GC-MS & Lee et al., 2001 \\
\hline 16 EPA-PAHs & $\begin{array}{l}\text { Ultrasonic extraction } 3 \text { times with dichloromethane, rotary evaporation, silica } \\
\text { alumina column, clean-up, elute with dichloromethane/hexane }\end{array}$ & GC-MS & Bi et al., 2003 \\
\hline 11 PAHs & Ultrasonic extraction with dichloromethane, rotary evaporation & GC-MS & $\begin{array}{l}\text { Chetwittayachan et al., } \\
2002\end{array}$ \\
\hline 15 PAHs & $\begin{array}{l}\text { Soxhlet extraction with dichloromethane/petroleum ether for } 24 \mathrm{~h} \text {, } \\
\text { K-D concentration. alumina silica column clean-up, elute with dichloromethane }\end{array}$ & GC-MS & Bae et al., 2002 \\
\hline 16 EPA-PAHs & Extraction with methylene chloride, concentration & HPLC-UVD & Lee and Lee, 2004 \\
\hline 8 PAHs & Subcritical water extraction, transfer into dichloromethane. concentration & GC-MS & Romero et al., 2002 \\
\hline 16 EPA-PAHs & Micro pressurized liquid extraction & GC & Zhou et al., 2005b \\
\hline 16 EPA-PAHs & Ultrasonic extraction with dichloromethane, evaporation & HPLC-FLD & Venkataraman et al., 2002 \\
\hline 16 EPA-PAHs & $\begin{array}{l}\text { Ultrasonic extraction } 3 \text { times with dichloromethane. rotary evaporation, } \\
\text { silica column clean-up }\end{array}$ & GC-MS & Duan et al., 2005 \\
\hline 16 EPA-PAHs & Accelerated solvent extraction with dichloromethane, clean-up & GC-MS & Wu et al., 2006 \\
\hline 16 EPA-PAHs & $\begin{array}{l}\text { Ultrasonic extraction } 3 \text { times with dichloromethane, rotary evaporation, } \\
\text { silica column clean-up. elute with hexane/dichloromethane }\end{array}$ & $\begin{array}{l}\text { GC-MS } \\
\text { GC-FID }\end{array}$ & Niu et al., 2005 \\
\hline 13 PAHs & Pressurized fluid extraction & GC-MS & Perraudin et al., 2005 \\
\hline 16 EPA-PAHs & $\begin{array}{l}\text { Soxhlet extraction with dichloromethane and dimethylsulfoxide for } 18 \mathrm{~h} \text {, } \\
\text { concentration, silica gel column clean-up }\end{array}$ & GC-MS & Dallarosa et al., 2005 \\
\hline 12 PAHs & Ultrasonic extraction with acetonitrile, rotary evaporation & RP-HPLC-FLD & Terzi and Samara, 2005 \\
\hline 9 PAHs & Ultrasonic extraction twice with benzene/ethanol (3/1), evaporation & HPLC-FLD & Tang et al., 2005 \\
\hline 16 EPA-PAHs & Ultrasonic extraction 3 times with dichloromethane, K-D concentration & HPLC-FLD & Zhang et al., 2005 \\
\hline 13 PAHs & Supercritical fluid extraction & HPLC & Jonker et al., 2005 \\
\hline 16 EPA-PAHs & Ultrasonic extraction & $\begin{array}{l}\text { HPLC-FLD } \\
\text { HPLC-UVD }\end{array}$ & $\begin{array}{l}\text { Sanderson and Farant, } \\
2005\end{array}$ \\
\hline 15 PAHs & $\begin{array}{l}\text { Ultrasonic extraction } 3 \text { times with dichloromethane. column separation, } \\
\text { rotary evaporation }\end{array}$ & GC-MS & Tan et al., 2005 \\
\hline 23 PAHs & $\begin{array}{l}\text { Soxhlet extraction with dichloromethane/acetone }(4 / 1) \text {, evaporation. } \\
\text { alumina column chromatography, elute with dichloromethane }\end{array}$ & GC-MS & $\begin{array}{l}\text { Yassaa and Cecinato, } \\
2005\end{array}$ \\
\hline 24 PAHs & $\begin{array}{l}\text { Soxhlet extraction with } n \text {-hexane for } 24 \mathrm{~h} \text {, rotary evaporation, silica gel column } \\
\text { clean-up, elute with } n \text {-hexane/toluene }\end{array}$ & GC-MS & $\begin{array}{l}\text { Tsapakis and Stephanou, } \\
2005 b\end{array}$ \\
\hline 17 PAHs & $\begin{array}{l}\text { Ultrasonic extraction with dichloromethane, rotary evaporation. silica } \\
\text { gel column clean-up, elute with dichloromethane }\end{array}$ & GC-MS & Zhou et al., 2005a \\
\hline 16 EPA-PAHs & Soxhlet extraction with dichloromethane $/ n$-hexane $(1 / 1)$ for $8 \mathrm{~h}$. rotary evaporation & GC-MS & Bourotte et al., 2005 \\
\hline
\end{tabular}




\begin{tabular}{|c|c|c|c|}
\hline Analyte & Pretreatment method & Analytical method & Reference \\
\hline 36 PAHs & $\begin{array}{l}\text { Soxhlet extraction with dichloromethane for } 24 \mathrm{~h} \text {, rotary evaporation, } \\
\text { alumina column clean-up, elute with dichloromethane/hexane }\end{array}$ & GC-MS & Gigliotti et al., 2005 \\
\hline 21 PAHs & Ultrasonic extraction with dichloromethane, centrifugation, evaporation under $\mathrm{N}_{2}$ & HPLC-FLD & Ohura et al., 2005 \\
\hline 15 PAHs & $\begin{array}{l}\text { Ultrasonic extraction } 3 \text { times with dichloromethane, rotary evaporation, silica gel } \\
\text { column separation }\end{array}$ & $\begin{array}{l}\text { GC-FID } \\
\text { GC-MS }\end{array}$ & Zheng et al., 2000 \\
\hline $10 \mathrm{PAHs}$ & Ultrasonic extraction with dichloromethane, $K-D$ concentration & GC-MS & Li et al., 2004 \\
\hline $11 \mathrm{PAHs}$ & Soxhlet extraction with dichloromethane/cyclohexane for $3 \mathrm{~h}$, evaporation & RP-HPLC-FLD & Besombes et al., 2001 \\
\hline 30 PAHs & Ultrasonic extraction with dichloromethane, rotary evaporation, clean-up & GC-MS & Naumova et al., 2003 \\
\hline 16 EPA-PAHs & Ultrasonic extraction with dichloromethane, evaporation & GC-MS & Park et al., 2002 \\
\hline $14 \mathrm{PAHs}$ & Ultrasonic extraction 3 times with dichloromethane, rotary evaporation & GC-MS & Chen et al., 2005 \\
\hline 16 EPA-PAHs & Soxhlet extraction with dichloromethane, rotary evaporation, clean-up & $\begin{array}{l}\text { HPLC-PAD/FLD } \\
\text { GC-MS } \\
\text { Biological analysis }\end{array}$ & Ciganek et al., 2004 \\
\hline
\end{tabular}

methods mostly used; Soxhlet extraction and ultrasonic extraction are the extraction methods mostly applied in the pretreatment.

\section{Expectations}

Atmospheric PAHs pollution has become a serious problem in the world. More and more researchers have put effort into this field. Though there are many reports on toxicity, concentration, distribution of PAHs and their derivatives, there are still many unknown mutagenic compounds of PAHs which are too low to be detected but have high mutagenicity. How to avoid the volatilization and loss of PAHs in the sampling, the reaction between PAHs and other compounds and the redistribution among different size particles; and how to develop new, noiseless and lower-volume sampler; to realize the pretreatment automatically, innocuously, rapidly, low-cost; to protect people's health from PAHs; all these problems need further endeavors.

\section{References}

Alebic-Juretic A, Critos T, Klesmic L, 1990. Hetergeneous polycyclic aromatic hydrocarbon degradation with ozone on silica gel carrier[J]. Environ Sci Technol, 24: 62-66.

Allen J O, Dookeran N M, Smith K A et al., 1996. Measurement of polycyclic aromatic hydrocarbons associated with size-segregated atmospheric aerosols in Massachusetts[J]. Environ Sci Technol, 30: 1023-1031.

Ames B N, Mccann J, Yamasaki E, 1975. Method for detecting carcinogens and mutagens with the salmonella/mammalianmicrosome mutagenicity test [J]. Mutat Res, 31: 347-364.

Angerer J, Mannschreck C, Gundel J, 1997. Biological monitoring and biochemical effect monitoring of exposure to polycyclic aromatic hydrocarbons[J]. Int Arch Occup Environ Health, 70: 365-377.

Bae S Y, Yi S M, Kim Y P, 2002. Temporal and spatial variations of the particle size distribution of PAHs and their dry deposition fluxes in Korea[J]. Atmos Environ, 36: 54915500.

Baek S O, Field R A, Goldstone M E et al., 1991. A review of atmospheric polycyclic aromatic hydrocarbons: sources, fate, and behavior[J]. Water Air Soil Poll, 60: 279-300.
Barzegar M, Dasgupta P, 1996. Liquid chromatographic determination of nitro-substituted polynuclear aromatic hydrocarbons by sequential electrochemical and fluorescence detection[J]. Anal Chem, 68: 1226-1232.

Bayona J M, Casellas M, Fernandez P et al, 1994. Sources and seasonal variability of mutagenic agents in the Barcelona city aerosol[J]. Chemosphere, 29: 441-450.

Besombes J, Maitre A, Patissier O et al., 2001. Particulate PAHs observed in the surrounding of a municipal incinerator[J]. Atmos Environ, 35: 6093-6104.

Bezabeh D Z, Holly H A, Schantz M M et al., 2003. Determination of nitrated polycyclic aromatic hydrocarbons in diesel particulate-related standard reference materials by using gas chromatography/mass spectrometry with negative ion chemical ionization[J]. Anal Bioanal Chem, 375: 381388.

Bi X H, Sheng G Y, Peng P A et al., 2003. Distribution of particulate- and vapor-phase $n$-alkanes and polycyclic aromatic hydrocarbons in urban atmosphere of Guangzhou, China[J]. Atmos Environ, 37: 289-298.

Bi X H, Sheng G Y, Peng P A et al., 2005. Size distribution of $n$-alkanes and polycyclic aromatic hydrocarbons (PAHs) in urban and rural atmospheres of Guangzhou, China[J]. Atmos Environ, 39: 477-487.

Bonfanti L, Careri M, Mangia A et al., 1996. Simultaneous identification of different classes of hydrocarbons and determination of nitro-polycyclic aromatic hydrocarbons by means of particle beam liquid chromatography-mass spectrometry[J]. J Chromatogr A, 728: 359-369.

Bostrfm C E, Grede P, Hanberg A et al., 2002. Cancer risk assessment, indicators, and guidelines for polycyclic aromatic hydrocarbons in the ambient air[J]. Environ Health Perspect, 110: 451- 488.

Bourotte C, Forti M, Taniguchi S et al., 2005. A wintertime study of PAHs in fine and coarse aerosols in Sao Paulo City, Brazil[J]. Atmos Environ, 39: 3799-3811.

Casellas M, Fernandez P, Bayona J M et al., 1995. Bioassaydirected chemical analysis of genotoxic components in urban airborne particulate matter from barcelone (Spain)[J]. Chemosphere, 30: 725-740.

Castells P, Santos F J, Galceran M T, 2003. Development of a sequential supercritical fluid extraction method for the analysis of nitrated and oxygenated derivatives of polycyclic aromatic hydrocarbons in urban aerosols[J]. J Chromatogr A, 1010: 141-151.

Cavalieri E, Rogan E, 1998. Mechanisms of tumor initiation by polycyclic aromatic hydrocarbons in mammals. In Neilson 
AH (ed.), The handbook of environmental chemistry, Vol. 3, Part J. PAHs and related compounds[M]. Berlin: SpringerVerlag. 81-117.

Cecinato A, Marino F, Filippo P D et al., 1999. Distribution of $n$-alkanes, polynuclear aromatic hydrocarbons and nitrated polynuclear aromatic hydrocarbons between the fine and coarse fractions of inhalable atmospheric particulates[J]. $J$ Chromatogr A, 846: 255-264.

Cecinato A, Mabilia R, Marino F, 2000. Relevant organic components in ambient particulate matter collected at Svalbard Islands (Norway)[J]. Atmos Environ, 34: 5061-5066.

Cecinato A, Tomasi Sciano M C, di Menno di Bucchianico A, 2003. Organic aerosols in the air of Milan, Italy. The IIACNR measurement campaign of 2000-2001[J]. J Sep Sci, 26: $397-401$

Chen Y J, Sheng G Y, Bi X H et al., 2005. Emission factors for carbonaceous particles and polycyclic aromatic hydrocarbons from residential coal combustion in China[J]. Environ Sci Technol, 39: 1861-1867.

Chetwittayachan T, Shimazaki D, Yamamoto K, 2002. A comparison of temporal variation of particle-bound polycyclic aromatic hydrocarbons (pPAHs) concentration in different urban environments: Tokyo, Japan, and Bangkok, Thailand[J]. Atmos Environ, 36: 2027-2037.

Ciganek M, Neca J, Adamec V et al., 2004. A combined chemical and bioassay analysis of traffic-emitted polycyclic aromatic hydrocarbons[J]. Sci Total Environ, 334-335: 141-148.

Cvacka J, Barek J, Zima J et al., 1998. High-performance liquid chromatography of nitrated polycyclic aromatic hydrocarbons[J]. Analyst, 123: 9R-18R.

Dallarosa J B, Monego J G, Teixeira E C et al., 2005a. Polycyclic aromatic hydrocarbons in atmospheric particles in the metropolitan area of Porto Alegre, Brazil[J]. Atmos Environ, 39: 1609-1625.

Dallarosa J B, Teixeira E C, Pires M et al., 2005b. Study of the profile of polycyclic aromatic hydrocarbons in atmospheric particles $\left(\mathrm{PM}_{10}\right)$ using multivariate methods[J]. Atmos Environ, 39: 6587-6596

David L N, Mltchell D E, Kenneth B T et al., 1982. Identification of Nitroaromatics in Diesel Exhaust Particulate Using Gas Chromatography/Negative Ion Chemical Ionization Mass Spectrometry and Other Techniques[J]. Environ Sci Technol, 16: 206-213.

Duan J C, Bi X H, Tan J Het al., 2005. The differences of the size distribution of polycyclic aromatic hydrocarbons (PAHs) between urban and rural sites of Guangzhou, China[J]. Atmos Res, 78: 190-203.

Dusek B, Hajslova J, Kocourek V, 2002. Determination of nitrated polycyclic aromatic hydrocarbons and their precursors in biotic matrices[J]. J Chromatogr A, 982: 127-143.

Environmental Protection Agency (EPA), 1987. US particulate matter $\left(\mathrm{PM}_{10}\right)[\mathrm{S}]$.

Environmental Protection Agency (EPA), 1999. Determination of polycyclic aromatic hydrocarbons (PAHs) in ambient air using gas chromatography/mass spectrometry (GC/MS) [S] Second ed. Compendium Method TO-13A.

Fan Z H, Chen D H, Birla P et al., 1995. Modeling of nitropolycyclic aromatic hydrocarbon formation and decay in the atmosphere[J]. Atmos Environ, 29: 1171-1181.

Fang G, Wu Y, Chen M et al., 2004. Polycyclic aromatic hydrocarbons study in Taichung, Taiwan, during 2002-2003[J]. Atmos Environ, 38: 3385-3391

Fernandez P, Baynoa T M, 1992. Use of offline gel permeation chromatography-normal-coated liquid chromatography for determination of polycyclic aromatic compounds in environmental samples and standard reference materials[J]. J Chromatogr, 625: 141-149.

Finlayson-Pitts B J, Pitts J N, 1999. Chemistry of the upper and lower atmosphere[M]. San Diego, CA: Academic Press.

Galceran M T, Moyano E, 1993. Determination of oxygenated and nitro-substituted polycyclic aromatic hydrocarbons by HPLC and electrochemical detection[J]. Talanta, 40: 615621

Gigliotti C L, Totten L A, Offenberg J H et al., 2005. Atmospheric concentrations and deposition of polycyclic aromatic hydrocarbons to the mid-atlantic east coast region[J]. Environ Sci Technol, 39: 5550-5559.

Guo H, Lee S C, Ho K F et al., 2003. Particle-associated polycyclic aromatic hydrocarbons in urban air of Hong Kong[J]. Atmos Environ, 37: 5307-5317.

Hafner W D, Hites R A, 2005. Effects of wind and air trajectory directions on atmospheric concentrations of persistent organic pollutants near the Great Lakes[J]. Environ Sci Technol, 39: 7817-7825.

Hayakawa K, Butoh M, Miyazaki M, 1992. Determination of dinitro- and nitropyrenes in emission particulates from diesel and gasoline engine vehicles by liquid chromatography with chemiluminescence detection after precolumn reduction[J]. Anal Chim Acta, 266: 251-256.

Hayakawa K, Terai N, Suzuki K et al., 1993. Chromatographic determination method for 1-nitropyrene and its metabolites in biological samples with fluorescence detection after online reduction[J]. Biomed Chromatogr, 7: 262-266.

Hayakawa K, Kawaguchi Y, Murahashi T et al., 1995a. Distributions of nitropyrenes and mutagenicity in airborne particulates collected with an Andersen sampler[J]. Mutat Res, 348: 57-61.

Hayakawa K, Murahashi T, Butoh M et al., 1995b. Determination of 1,3-, 1,6-, and 1,8-dinitropyrenes and 1-nitropyrene in urban air by high-performance liquid chromatography using chemiluminescence detection[J]. Environ Sci Technol, 29: 928-932.

Hayakawa K, Murahashi T, Noji K et al., 1999a. Columnswitching high performance liquid chromatography for determining polycyclic aromatic hydrocarbons and nitropolycyclic aromatic hydrocarbons in environmental samples[J]. Chromatogr J Sep Detect Sci, 20: 255-262.

Hayakawa K, Kizu R, Ando K, 1999b. Study on atmospheric behavior and toxicity of carcinogenic nitroarenes by high-performance liquid chromatography using chemiluminescence detection[J]. Chromatogr J Sep Detect Sci, 20: $37-43$.

Hayakawa K, 2000. Chromatographic methods for carcinogenic/mutagenic nitropolycyclic aromatic hydrocarbons[J]. Biomed Chromatogr, 14: 397-405.

Hayakawa K, Tang N, Akutsu K et al., 2002. Comparison of polycyclic aromatic hydrocarbons and nitropolycyclic aromatic hydrocarbons in airborne particulates collected in downtown and suburban Kanazawa, Japan[J]. Atmos Environ, 36: 5535-5541.

IARC, 1983. Polynuclear aromatic compounds. Part 1, chemical, environmental and experimental data. In IARC monographs on the evaluation of the carcinogenic risk of chemicals to humans[Z]. vol. 32. International Agency for research on Cancer, Lyon. 453

International Programme on Chemical Safety (IPCS), 1998. Environmental Health Criteria 202. Selected NonHeterocyclic Polycyclic Aromatic Hydrocarbons[Z]. World 
Health Organization, Geneva.

Jacob J, Karcher W, Belliardo J J et al, 1991. Polycyclic aromatic compounds of environmental and occupational importance-Their occurrence, toxicity and the development of high-purity certified reference materials Part III[J]. Fresenius J Anal Chem, 340: 755-767.

Jin Z L, Rappaport S M, 1983. Microbore liquid chromatography with electrochemical detection for determination of nitrosubstituted polynuclear aromatic hydrocarbons in diesel soot[J]. Anal Chem, 55: 1778-1781.

Jonker M T O, Hawthorne S B, Koelmans A A, 2005. Extremely slowly desorbing polycyclic aromatic hydrocarbons from soot and soot-like materials: evidence by supercritical fluid extraction[J]. Environ Sci Technol, 39: 7889-7895.

Kameda Y, Shirai J, Komai T et al., 2005. Atmospheric polycyclic aromatic hydrocarbons: size distribution, estimation of their risk and their depositions to the human respiratory tract[J]. Sci Total Environ, 340: 71-80.

Kirton P J, Crisp P T, 1990. The sampling of coke oven emissions for polycyclic aromatic hydrocarbons: a critical review[J]. Fuel, 69: 633-638.

Kolar K, Ciganek M, Malecha J, 2004. Air/polymer distribution coefficients for polycyclic aromatic hydrocarbons by solidphase microextraction sampling[J]. J Chromatogr A, 1029: 263-266.

Kozin I, Gooijer C, Velthorst N H et al., 1996. Isomer-specific detection of PAHs and PAH metabolites in environmental matrices by shpol'skii luminescence spectroscopy[J]. Chemosphere, 33: 1435-1447.

Koziel J A, Odziemkowski M, Pawliszyn J, 2001. Sampling and analysis of airborne par ticulate matter and aerosols using in-needle trap and SPME fiber devices[J]. Anal Chem, 73: 47-54.

Kuo C T, Chen $\mathrm{H}$ W, Lin S T, 2003. Trace determination of nitrated polycyclic aromatic hydrocarbons using liquid chromatography with on-line electrochemical reduction and fluorescence detection[J]. Anal Chim Acta, 482: 219-228.

Lee B, Lee C, 2004. Development of an improved dry and wet deposition collector and the atmospheric deposition of PAHs onto Ulsan Bay, Korea[J]. Atmos Environ, 38: 863871.

Lee C W, Lemieux P M, Gullett B K et al., 1998. Research on emissions and mitigation of POPs from combustion sources[J]. Stud Environ Sci, 72: 361-378.

Lee S C, Ho K F, Chan L Y et al., 2001. Polycyclic aromatic hydrocarbons (PAHs) and carbonyl compounds in urban atmosphere of Hong Kong[J]. Atmos Environ, 35: 59495960.

Lee W J, Wang Y F, Lin T C et al., 1995. PAH characteristics in the ambient air of traffic-source[J]. Sci Total Environ, 159: 185-200.

Li C S, Ro Y S, 2000. Indoor characteristics of polycyclic aromatic hydrocarbons in the urban atmosphere of Taipei[J]. Atmos Environ, 34: 611-620.

Li K, Chen R, Zhao B et al., 1999. Monoclonal antibody-based ELISAs for part-per-billion determination of polycyclic aromatic hydrocarbons: effects of haptens and formats on sensitivity and specificity[J]. Anal Chem, 71: 302-309.

Li L B, Xie H L, Jiang H W, 2004. Distribution of polycyclic aromatic hydrocarbons on different diametral atmospheric particulates[J]. $J$ Environ Health, 21: 153-154.

Lin T, Chang F, Hsieh J et al., 2002. Characteristics of polycyclic aromatic hydrocarbons and total suspended particulate in indoor and outdoor atmosphere of a Taiwanese temple[J]. J
Hazard Mater, A95: 1-12.

Lohmann R, Corrigan B P, Howsam M et al., 2001. Further developments in the use of semipermeable membrane devices (SPMDs) as passive air samplers for persistent organic pollutants: field application in a spatial survey of PCDD/Fs and PAHs[J]. Environ Sci Technol, 35: 2576- 2582.

Marino F, Cecinato A, Siskos P A, 2000. Nitro-PAH in ambient particulate matter in the atmosphere of Athens[J]. Chemosphere, 40: 533-537.

Marr L C, Kirchstetter T W, Harley R A et al., 1999. Characterization of polycyclic aromatic hydrocarbons in motor vehicle fuels and exhaust emissions[J]. Environ Sci Technol, 33: 3091-3099.

Mastral A M, Callen M S, Garcia T, 2000a. Fluidized bed combustion (FBC) of fossil and nonfossil fuels. A comparative study[J]. Energ Fuel, 14: 275-281.

Mastral A M, Callen M S, Garcia T, 2000b. Polyaromatic environmental impact in coal-tire blend atmospheric fluidized bed (AFB) combustion[J]. Energ Fuel, 14: 164-168.

Mastral A M, Callen M S, Murillo R et al., 1999. Polycyclic aromatic hydrocarbons and organic matter associated to particulate matter emitted from atmospheric fluidized bed coal combustion[J]. Environ Sci Technol, 33: 3177-3184.

Mastral A M, Garcia T, Callen M S et al., 2001. Effects of limestone on polycyclic aromatic hydrocarbon emissions during coal atmospheric fluidized bed combustion[J]. Energ Fuel, 15: 1469-1474.

Matsuzawa S, Garrigues P, Budzinski $\mathrm{H}$ et al., 1995. Applicability of low temperature high-resolution fluorescence spectroscopy to the analysis of nitro and amino polycyclic aromatic hydrocarbons[J]. Anal Chim Acta, 312: 165-177.

Mersch-Sudermann V, Mochayedi S, Kevekordes S et al., 1993. The genotoxicity of unsubstituted and nitrated polycyclic aromatic hydrocarbons[J]. Anticancer Res, 13: 2037-2044.

Moreira J C, Kuriyama G S, Barek J, 1996. Proceedings of the national conference on polycyclic aromatic hydrocarbons in general and industrial environment[C]. Garga, 63 .

Murayama M, Dasgupta P K, 1996. Liquid chromatographic determination of nitro-substituted polynuclear aromatic hydrocarbons by sequential electrochemical and fluorescene detection[J]. Anal Chem, 68: 1226-1232.

Naumova Y Y, Offenberg J H, Eisenreich S J et al., 2003. Gas/particle distribution of polycyclic aromatic hydrocarbons in coupled outdoor/indoor atmospheres[J]. Atmos Environ, 37: 703-719.

Niu H Y, Wang H, Wang G $\mathrm{H}$ et al., 2005. Source identification and pollution evaluation of polycyclic aromatic hydrocarbons in atmospheric aerosols in Nanjing City[J]. China Environ Sci, 25: 544-548.

Oamh N T, Reutergardh L B, Dung N T, 1999. Emission of polycyclic aromatic hydrocarbons and particulate matter from domestic combustion of selected fuels[J]. Environ Sci Technol, 33: 2703-2709.

Ochsenkuhn-Petropoulou M, Staikos K, Matuschek G et al., 2003. On-line determination of polycyclic aromatic hydrocarbons in airborne particulate matter by using pyrolysis/GC-MS[J]. J Anal Appl Pyrol, 70: 73-85.

Ohura T, Amagai T, Sugiyama $T$ et al., 2004. Characteristics of particle matter and associated polycyclic aromatic hydrocarbons in indoor and outdoor air in two cities in Shizuoka, Japan[J]. Atmos Environ, 38: 2045-2054.

Ohura T, Noda T, Amagai T et al., 2005. Prediction of personal exposure to $\mathrm{PM}_{2.5}$ and carcinogenic polycyclic aromatic hydrocarbons by their concentrations in residential $\mathrm{mi}$ - 
croenvironments[J]. Environ Sci Technol, 39: 5592-5599.

Okuda $\mathrm{T}$, Kumata $\mathrm{H}$, Naraoka $\mathrm{H}$ et al., 2002. Origin of atmospheric polycyclic aromatic hydrocarbons (PAHs) in Chinese cities solved by compound-specific stable carbon isotopic analyses[J]. Org Geochem, 33: 1737-1745.

Park S S, Kim Y J, Kang C H, 2002. Atmospheric polycyclic aromatic hydrocarbons in Seoul, Korea[J]. Atmos Environ, 36: $2917-2924$

Peltonen K, Kuljukka T, 1995. Air sampling and analysis of polycyclic aromatic hydrocarbons[J]. J Chromatogr A, 710: 93-108.

Perraudin E, Budzinski H, Villenave E, 2005. Analysis of polycyclic aromatic hydrocarbons adsorbed on particles of atmospheric interest using pressurised fluid extraction[J]. Anal Bioanal Chem, 383: 122-131.

Pitts J N, Van C K A, Schmid J P et al., 1978. Atmospheric reactions of polycyclic aromatic hydrocarbons: facile formation of mutagenic nitro derivatives[J]. Science, 202: 515-519.

Possanzini M, Palo V D, Gigliucci P et al, 2004. Determination of phase-distributed PAH in Rome ambient air by denuder/GC-MS method[J]. Atmos Environ, 38: 17271734.

Ramdahl T, Urdal K, 1982. Determination of nitrated polycyclic aromatic hydrocarbons by fused silica capillary gas chromatography/negative ion chemical ionization mass spectrometry[J]. Anal Chem, 54: 2256-2260.

Romero R, Sienra R, Richter P, 2002. Efficient screening method for determination of polycyclic aromatic hydrocarbons (PAHs) in airborne particles. Application in real samples of Santiago-Chile metropolitan urban area[J]. Atmos Environ, 36: 2375-2381.

Sanderson E G, Farant J P, 2005. Atmospheric size distribution of PAHs: evidence of a high-volume sampling artifact[J]. Environ Sci Technol, 39: 7631-7637.

Schnelle-Kreis J, Gebefugi I, Welzl G et al., 2001. Occurrence of particle-associated polycyclic aromatic compounds in ambient air of the city of Munich[J]. Atmos Environ, 35 (Supplement): S71-S81

Sheu H, Lee W, Lin S J et al., 1997. Particle-bound PAH content in ambient air[J]. Environ Pollut, 96: 369-382.

Shimmo M, Anttila P, Hartonen K et al., 2004. Indertification of organic compounds in atmospheric aerosol particles by online supercritical fluid extraction-liquid chromatographygas chromatography-mass spectrometry[J]. J Chromatogr A, 1022: 151-159.

Siegmund B, Weiss R, Pfannhauser W, 2003. Sensitive method for the determination of nitrated polycyclic aromatic hydrocarbons in the human diet[J]. Anal Bioanal Chem, 375: 175-181.

Silvestre B T, Roy B Z, John E S, 1986. Fluorescence detection and identification of nitro derivatives of polynuclear aromatic hydrocarbons by on-column catalytic reduction to aromatic amines[J]. Anal Chem, 58: 1827-1834.

Simcik M F, Eisenreich S J, Lioy P J, 1999. Source apportionment and source/sink relationships of PAHs in the coastal atmosphere of Chicago and Lake Michigan[J]. Atmos Environ, 33: 5071-5079.

Soderstrom H, Bergqvist P, 2004. Passive air sampling using semipermeable membrane devices at different wind-speeds in situ calibrated by performance reference compounds[J]. Environ Sci Technol, 38: 4828-4834.

Soderstrom H, Hajslova J, Kocourek V et al,, 2005. PAHs and nitrated PAHs in air of five European countries determined using SPMDs as passive samplers[J]. Atmos Environ, 39:
$1627-1640$.

Song G Q, Lin J M, 2005. Sample pretreatment techniques for polycyclic aromatic hydrocarbons in environmental matrix[J]. Acta Scientiae Circumstantiae, 25; 1287-1296.

Taga R, Tang N, Hattori T et al., 2005. Direct-acting mutagenicity of extracts of coal burning-derived particulates and contribution of nitropolycyclic aromatic hydrocarbons[J]. Mutat Res, 581: 91-95.

Tan J H, Bi X H, Duan J C et al., 2005. Seasonal variation of particulate polycyclic aromatic hydrocarbons associated with $\mathrm{PM}_{10}$ in Guangzhou[J], China. Acta Scientiae Circumstantiae, 25: 855-862.

Tang N, Toriba A, Kizu R et al., 2003. Improvement of an automatic HPLC system for nitropolycyclic aromatic hydrocarbons: removal of an interfering peak and increase in the number of analytes[J]. Anal Sci, 19: 249-253.

Tang N, Taga R, Hattori $T$ et al., 2004. Determination of atmosperic nitrobenzanthrones by high-performance liquid chromatrography with chemiluminescence detection[J]. Anal Sci, 20: 119-123.

Tang N, Hattori T, Taga $\mathrm{R}$ et al., 2005. Polycyclic aromatic hydrocarbons and nitropolycyclic aromatic hydrocarbons in urban air particulates and their relationship to emission sources in the Pan-Japan Sea countries[J]. Atmos Environ, 39: $5817-5826$

Tejada S B, Zweidinger R B, Sigsby J E, 1986. Fluorescence detection and identification of nitro derivatives of polynuclear aromatic hydrocarbons by on-column catalytic reduction to aromatic amines[J]. Anal Chem, 58: 1827-1834.

Terzi E, Samara C, 2005. Dry deposition of polycyclic aromatic hydrocarbons in urban and rural sites of Western Greece[J]. Atmos Environ, 39: 6261-6270.

Tsai P, Shieh H, Lee W et al., 2002. Characterization of PAHs in the atmosphere of carbon black manufacturing workpiaces[J]. J Hazard Mater, A91: 25-42.

Tsapakis M, Stephanou E G, 2005a. Occurrence of gaseous and particulate polycyclic aromatic hydrocarbons in the urban atmosphere: study of sources and ambient temperature effect on the gas/particle concentration and distribution[J]. Environ Pollut, 133: 147-156.

Tsapakis M, Stephanou E G, 2005b. Polycyclic aromatic hydrocarbons in the atmosphere of the Eastern Mediterranean[J]. Environ Sci Technol, 39: 6584-6590.

United Nations Economic Commission for Europe (UN ECE), 1998. ECE/EB [Z]. Air/60.

Vardar N, Tasdemir Y, Odabasi M et al., 2004. Characterization of atmospheric concentrations and partitioning of PAHs in the Chicago atmosphere[J]. Sci Total Environ, 327: 163174

Vasconcellos P C, Zacarias D, Pires M A F et al., 2003. Measurements of polycyclic aromatic hydrocarbons in airborne particles from the metropolitan area of Sao Paulo City, Brazil[J]. Atmos Environ, 37: 3009-3018.

Venkataraman C, Thomas S, Kulkarni P, 1999. Size distributions of polycyclic aromatic hydrocarbons-gas/particle partitioning to urban aerosols[J]. J Aerosol Sci, 30: 759-770.

Venkataraman C, Negi G, Sardar S B et al., 2002. Size distributions of polycyclic aromatic hydrocarbons in aerosol emissions from biofuel combustion[J]. J Aerosol Sci, 33: 503-518.

Vestreng V, Klein $H, 2002$. Emission data reported to UNECE/EMEP: Quality Assurance and Trend Analysis and Presentation of WebDab. MSC-W Status Report 2002[C]. EMEP-MSC-W Note 1/ 2002. Meteorological Synthesizing 
Centre-West. Oslo, Norway.

WHO, 2000. Air quality guidelines for Europe[M]. Second ed. WHO Regional Publications, European series No. 91, Copenhagen.

WHO/IPCS, 1998. Selected non-heterocyclic polycyclic aromatic hydrocarbons[Z], Environmental Health Criteria 202, Geneva.

Wilhelm M, Matuschek G, Kettrup A, 2000. Determination of basic nitrogen-containing polynuclear aromatic hydrocarbons formed during thermal degradation of polymers by high-performance liquid chromatography-fluorescence detection[J]. J Chromatogr A, 878: 171-181.

Wu S P, Tao S, Liu W X, 2006. Particle size distributions of polycyclic aromatic hydrocarbons in rural and urban atmosphere of Tianjin, China[J]. Chemosphere, 62: 357367.

Xu J H, Lee F S, 2000. Quantification of nitrated polynuclear aromatic hydrocarbons in atmospheric particulate matter[J]. Anal Chim Acta, 416: 111-115.

$\mathrm{Xu} \mathrm{J} \mathrm{H,} \mathrm{Lee} \mathrm{F} \mathrm{S,} \mathrm{2001.} \mathrm{Analysis} \mathrm{of} \mathrm{nitrated} \mathrm{polynuclear} \mathrm{aromatic}$ hydrocarbons $[J]$. Chemosphere, 42: 245-250.

Xu S S, Liu W X, Tao S, 2006. Emission of polycyclic aromatic hydrocarbons in China[J]. Environ Sci Technol, 40: 702708.

Xu X B, Burlingame A L, 1988. Environmental applications of organic mass spectrometry in China[J]. Biomed Environ Sci, 1: 253-269.

Yang Y, Gharaibeh A, Hawthorne S B, 1995. Combined temperature/modifier effects on supercritical $\mathrm{CO}_{2}$ extraction efficiencies of polycyclic aromatic hydrocarbons from environmental samples[J]. Anal Chem, 67: 641-646.

Yang P, Gong B F, Xiong Y et al., 1999. Study of soxhlet extraction of polycyclic aromatic hydrocarbons on airborne particulate[J]. Environ Monit China, 15: 16-20.

Yassaa N, Cecinato A, 2005. Composition of torched crude oil organic particulate emitted by refinery and its similarity to atmospheric aerosol in the surrounding area[J]. Chemosphere, 60: 1660-1666.

Yu D, Berlin J A, Penning T M et al., 2002. Reactive oxygen species generated by PAH o-quinones cause change-infunction mutations in p53[J]. Chem Res Toxicol, 15: 832-842.

Yutaka K, Junko S, Takeshi K et al., 2005. Atmospheric polycyclic aromatic hydrocarbons: size distribution, estimation of their risk and their depositions to the human respiratory tract[J]. Sci Total Environ, 340: 71-80.

Zhang Z Q, Xu S C, Wang Y, 2005. The concentration and distribution of some organic matter in the aerosol of Qingdao coast[J]. Periodical of ocean university of China, 35: 661664.

Zheng M, Fang M, Wang F et al., 2000. Characterization of the solvent extractable organic compounds in $\mathrm{PM}_{2.5}$ aerosols in Hong Kong[J]. Atmos Environ, 34: 2691-2702.

Zhou J B, Wang T G, Huang Y B et al,, 2005a. Seasonal variation character of polycyclic aromatic hydrocarbons in atmospheric $\mathrm{PM}_{10}$ of partial areas in Beijing[J]. China Environ Sci, 25: 115-119.

Zhou Y S, Liu W M, Zhao J H et al., 2005b. Determination of 16 polycyclic aromatic hydrocarbons in atmospheric particulate matters by on-line micro-pressurized liquid extraction coupled with capillary gas chromatography[J]. Chinese J Anal Chem, 33: 1231-1234.

Zhu L, Wang J, 2003. Sources and patterns of polycyclic aromatic hydrocarbons pollution in kitchen air, China[J]. Chemosphere, 50: 611-618.

Zimmermann R, Heger H J, Kettrup A, 1999. On-line monitoring of traces of aromatic-, phenolic-, and chlorinated components in flue gases of industrial scale incinerators and cigarette smoke by direct-inlet laser ionization mass spectrometry (REMPI-TOFMS)[J]. Fresen J Anal Chem, 363: 720-730. 